Trakya Üniversitesi

Eğitim Fakültesi Dergisi

Cilt 8, Say 2

Ocak 2018 195-213

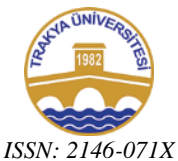

ISSN: 2146-071X
Trakya University

Journal of Education Faculty

Volume 8, Issue 2

January 2018, 195-213

Geliş Tarihi: 05.02.2017

Doi: $10.24315 /$ trkefd.310112

\title{
Sınıf Öğretmeni Adaylarının STEM Eğitimine Yönelik Görüşleri: Uygulamalı Bir Çalışma
}

\section{Pre-Service Primary School Teachers' Views about STEM Education: An Applied Study}

\section{Bekir YILDIRIM ${ }^{1}$, Cumhur TÜRK ${ }^{2}$}

\begin{abstract}
Öz: $\mathrm{Bu}$ araştırmada sınıf öğretmeni adaylarının STEM eğitimine yönelik görüşlerini incelemek amaçlanmıştır. Araştırmanın çalışma grubunu 40 sınıf ögretmeni adayı oluşturmaktadır. Durum çalışma deseni olarak yürütülen bu çalışma 2016-2017 eğitim-öğretim yılı güz döneminde 12 haftada (haftada 4 saat) tamamlanmıştır. Veri toplama aracı olarak araştırmacılar tarafından geliştirilen yarı yapılandırılmış görüşme formu kullanılmıştır. Elde edilen veriler içerik analiz basamaklarına uygun olarak analiz edilmiştir. STEM eğitimi uygulamaları sonucunda öğretmen adaylarının STEM eğitimi ve mühendislik-teknolojiye yönelik olarak düşüncelerinin olumlu yönde değiştiği tespit edilmiştir. Öğretmen adayları STEM eğitiminin ilköğretim ve okulöncesi dönemlerinde kullanılmasının önemli olduğunu belirtmişlerdir. Ayrıca ögretmen adayları, STEM eğitimi sayesinde çocukların yaratıcılık, hayal gücü, merak, özgüven, sorumluluk, empati gibi birçok özelliğinin gelişebileceği yönünde görüşler bildirmişlerdir. Sonuçlar doğrultusunda sınıf öğretmenliği lisans programında STEM eğitimi verilmesini sağlayacak seçmeli veya zorunlu derslerin açılması önerilmiştir.
\end{abstract}

Anahtar sözcükler: STEM Ĕgitimi, ögrretmen adayl, durum çalışması

\begin{abstract}
The objective of this study is to examine the views of pre-service primary school teachers about STEM education. Thus, the study group consists of 40 pre-service primary school teachers. This case study was completed in 12 weeks (4 hours a week) during 2016-2017 Academic Year fall semester. A semi-structured interview form developed by the researchers was used as data collection tool. The data obtained were analyzed in line with content analysis steps. As a result of STEM education instruction, it was found that pre-service teachers' views for STEM education and engineering-technology changed positively. Pre-service teachers stated that it was important to use STEM education in primary school and pre-school periods. In addition, pre-service teachers have stated that STEM education can develop children's many characteristics such as creativity, imagination, curiosity, self - confidence, responsibility, empathy. In line with the results, it was suggested that compulsory or optional courses of STEM education should be provided in the undergraduate program of primary school teaching.
\end{abstract}

Keywords: STEM Education, pre-service teacher, case study

\footnotetext{
${ }^{1}$ Yrd. Doç. Dr., Muş Alparslan Üniversitesi, Matematik ve Fen Bilimleri Eğitim Bölümü, Fen Bilgisi Eğitimi Anabilim Dalı, e-posta: bekir58bekir@gmail.com

${ }^{2}$ Yrd. Doç. Dr., Muş Alparslan Üniversitesi, Temel Eğitim Bölümü, Okul Öncesi Eğitimi Anabilim Dalı, e-posta: c.turk@alparslan.edu.tr
} 


\section{GIRISS}

Son yıllarda disiplinler arası çalışmanın önem kazanmasıyla birlikte ülkeler bu yönde yenilikçi eğitim yaklaşımlarını benimsemişlerdir. Yenilikçi eğitim yaklaşımlarından biri de STEM'dir. STEM, fen, teknoloji, mühendislik ve matematik alanlarının entegre bir şekilde günlük yaşamla ilişkilendirilmesidir (Gonzalez \& Kuenzi, 2012; Y1ldırım \&Altun, 2014). STEM kavramı, ilk kez isim olarak 2001 yılında Amerika Birleşik Devletleri'nde (ABD) ortaya çıkmıştır. STEM isminin çıkış tarihi 2001 olmasına karşın asıl kökeni 1957 yılına dayanmaktadır. Bu kavramın ABD'de ortaya çıkmasının temelinde iki önemli husus bulunmaktadır. İlk olarak o dönemki Amerikalı öğrencilerin fen bilimleri, matematik ve mühendislik alanlarına olan ilgilerin azalması yatmaktadır (Ostler, 2012). İkinci olarak ise ABD'nin ekonomik ve teknolojik olarak uluslararası platformda geriye düşeceği endişesidir.

Fen ve matematik bilgisi, tecrübe ile bir araya geldiğinde mühendislik disiplini ortaya çıkmaktadır. Bu üç disiplin birleştiğinde ise teknolojik yenilikler meydana gelmektedir. Teknolojik ürünler beraberinde küresel yarışı ve ekonomik gücü getirmektedir. Bazı araştırmacılara göre teknoloji ekonomi için "gatekeeper" olarak adlandırılmaktadır (Dorsen, Carlson, \& Goodyear, 2006). Ekonomik ve teknolojik gelişmenin ortaya çıkabilmesi için yenilikçi (inovatif) ve yaratıcı düşünme becerilerinin geliştirilmesi gerekmektedir. $\mathrm{Bu}$ açılardan düşünüldügüunde, STEM eğitimi ekonomik ve teknolojik gelişmelere katkı sağladığı gibi yenilikçi ve yaratıcı düşünme becerilerini de geliştirmektedir. Yıldırım ve Altun'a (2015) göre, STEM eğitimi; farklı disiplinleri bir araya getiren, öğrencilerin etkili ve kaliteli öğrenmesine imkân veren, öğrenilen bilgilerin günlük yaşamla ilişkisini kurarak anlamlı öğrenmeyi sağlayan ve son olarak 21. yy. yaşam becerilerinin gelişmesine katk1 sunan bir yaklaşımdır. STEM eğitimi bireylerin yaratıcı düşünme, hayal gücü, empati ve hoşgörü gibi becerilerinin gelişmesini sağlayan ve onları 21. yy. işgücüne hazırlamada önemli olan bir yaklaşımdır (Ostler, 2012; Yıldırım, 2016a; Yıldırım \& Altun, 2015). STEM eğitiminin öğretme-öğrenme süreçlerinde uygulanmasında ise birinci dereceden sorumlu kişiler öğretmenlerdir (Wang, 2012; Wang, Moore, Roehring, \& Park, 2011). STEM eğitimini iyi bilen öğretmenler öğrencilere bir disiplini öğretirken diğer disiplinlerle de bağlantı kurarak, onların diğer disiplinleri de öğrenmesini sağlayacaktır. Diğer bir deyişle öğrenciler disiplinler arası bir şekilde konuyu öğreneceklerdir. Bu da STEM eğitiminin farklı boyutları olan disiplinler arası bir yaklaşım olduğunu ortaya koymaktadır. Söz konusu farklı boyutların yeterince anlaşılması ve uygulanması STEM eğitiminin amacına ulaşmasında önemlidir. Bunun yanı sıra STEM eğitiminin etkili bir biçimde derslere entegre edilmesi aşamasında, STEM alan bilgisi, STEM pedagoji bilgisi, STEM entegrasyon bilgisi, 21. yy. becerileri bilgisi ve bağlam bilgileri de gereklidir (Benuzzi, 2015; Hudson, English, Dawes, King, \& Baker, 2015; Rogers, Winship, \& Sun, 2015; Stohlmann, Moore, \& Roehrig, 2012).

$\mathrm{Bu}$ doğrultuda okul öncesi ve ilköğretimden itibaren çocukların hayal dünyaları sınırlandırılmadan, düşünme becerilerini ortaya koyabilecekleri, kendilerini ifade edebilecekleri, kendi düzeylerine uygun problemlerle karşı karşıya kalabilecekleri öğrenme ortamlarının oluşturulması önem arz etmektedir (Akbıyık \& Kalkan-Ay, 2014). Çocukların bu özelliklerin gelişmesinde STEM eğitimi önemlidir. Dolayısıyla bu durum STEM eğitiminin erken yaşlardan itibaren verilmesini gerektirmektedir. Bu noktada öğretmenlere önemli görevler düşmektedir. Çünkü öğrencilerin bu alanlara ilgi duyup, başarılı olmaları, onları eğitecek öğretmenlerin 
yeterli eğitim düzeyinde olmasıyla sağlanabilir. $\mathrm{Bu}$ nedenle sınıf öğretmeni adaylarının STEM eğitimi konusunda yeterli beceri ve donanıma sahip olmaları önemlidir.

\subsection{Araştırmanın Amacı}

$\mathrm{Bu}$ araştırmada STEM eğitimi uygulamaları sonrası, sınıf öğretmeni adaylarının STEM eğitimi, mühendislik, teknoloji ve STEM disiplinlerinin arasındaki ilişkiye yönelik görüşlerinin neler olduğunu belirlemek amaçlanmıştır. Bu amaç doğrultusunda aşağıdaki araştırma sorularına cevaplar aranmıştır.

- STEM eğitimi uygulamalarına yönelik sınıf öğretmeni adaylarının görüşleri nelerdir?

— STEM eğitimi uygulamaları sonucunda sınıf öğretmeni adaylarının mühendisliğe yönelik görüşleri nelerdir?

- STEM eğitimi uygulamaları sonucunda sınıf öğretmeni adaylarının teknolojiye yönelik görüşleri nelerdir?

- STEM eğitimi uygulamaları sonucunda sınıf öğretmeni adaylarının STEM disiplinleri arasındaki ilişkiye yönelik görüşleri nelerdir?

\section{YÖNTEM}

\subsection{Araştırma Deseni}

Araştırmada sınıf öğretmeni adaylarının STEM eğitimine yönelik görüşlerinin neler olduğunun belirlenmesi amaçlanmaktadır. Bu amaca uygun olarak, araştırmada nitel araştırma yöntemlerinden olan durum çalışması yöntemi kullanılmıştır. Durum çalışması, araştırmacının belli bir zaman dilimi içerisinde sınırlandırılmış bir veya birkaç durumun derinlemesine incelendiği, durumların ve duruma bağlı temaların tanımlandığı nitel bir araştırma yaklaşımıdır (Creswell, 2003). Durum çalışmalarının en önemli özelliği, bir ya da birkaç durumun derinlemesine araştırılmasını sağlar. Kısacası, bir duruma ilişkin faktörleri bütüncül bir yaklaşımla ele alır, durumu nasıl etkilediğini ve etkilerini ortaya koyar.

\section{2. Çalışma Grubu}

Araştırma 2016-2017 eğitim-öğretim y1lı güz döneminde bir devlet üniversitesinin "Fen Teknolojileri Öğretimi-I" adlı dersinde gerçekleştirilmiştir. Araştırmanın çalışma grubunu, Sınıf Öğretmenliği Anabilim Dalı 3. sınıf öğrencisi olan 50 öğretmen adayının arasından iki kriter doğrultusunda seçilen 40 öğretmen adayı oluşturmuştur. Bu kriterlerin birincisi, STEM eğitimi derslerine en az 10 hafta katılma, ikincisi ise STEM eğitiminin uygulama boyutunda (6 ile 12 hafta aras1) tamamen yer almadır. Araştırmada görüşlerine başvurulan sınıf öğretmeni adaylarına araştırma etiği gereği $\ddot{O}_{1}, \ddot{\mathrm{O}}_{2}, \ddot{\mathrm{O}}_{3}, \ldots \ddot{\mathrm{O}}_{39}$ ve $\mathrm{O}_{40}$ rumuzları verilmiştir.

\subsection{Uygulama Süreci}

Araştırmanın uygulama süreci 12 hafta (haftada 4 saat) sürmüştür. Gerçekleştirilen STEM uygulamalarına ilişkin bilgiler Tablo 1'de verilmiştir. 
Tablo 1. STEM uygulamalarına ilişskin program içerĭg i

\begin{tabular}{|c|c|}
\hline Hafta & İçerik \\
\hline 1. Hafta & STEM'in tanımı, nasıl ortaya çıktığı \\
\hline 2. Hafta & STEM eğitiminin önemi, ülkelerin mevcut durumları ve STEM disiplinleri \\
\hline 3. Hafta & Entegrasyonun ne olduğu, entegrasyon modellerinin neler olduğu \\
\hline 4. Hafta & $\begin{array}{l}\text { STEM eğitimi entegrasyon modellerinden olan } 5 \mathrm{E} \text { ögrenme modeli, bu modele } \\
\text { uygun ders planı hazırlama ve uygulama yapma }\end{array}$ \\
\hline 5. Hafta & $\begin{array}{l}\text { STEM eğitiminde proje tabanlı öğrenme, bu modele uygun ders planı } \\
\text { hazırlama ve uygulama yapma }\end{array}$ \\
\hline 6. Hafta & $\begin{array}{l}\text { STEM Student on Stage (SOS) modeli, bu modele uygun ders planı hazırlama } \\
\text { ve uygulama yapma }\end{array}$ \\
\hline 7. Hafta & STEM eğitimine uygun hazırlanan ders planlarının sınıfta uygulanması \\
\hline 8. Hafta & STEM eğitimine uygun hazırlanan ders planlarının sınıfta uygulanması \\
\hline 9. Hafta & $\begin{array}{l}\text { STEM eğitiminde proje tabanlı̈ örenmeye (STEMPTÖ) uygun hazırlanan ders } \\
\text { planları ile öğretmen adaylarına tahtalar verilerek "en dayanaklı köprü” } \\
\text { yaptırılmıştır. }\end{array}$ \\
\hline 10. Hafta & $\begin{array}{l}\text { 4. sınıf fen bilimleri dersi ögretim programına uygun STEM uygulamalarının } \\
\text { yapılması }\end{array}$ \\
\hline 11. $\mathbf{H}$ & STEM eğitiminde tam sayılar konusunun öğretilmesi ve asansör uygulaması \\
\hline 12. $\mathrm{H}$ & Yapılan etkinlerin değerlendirilmesi \\
\hline
\end{tabular}

\subsection{Veri Toplama Aracı}

Araştırma kapsamında sınıf öğretmeni adaylarının STEM eğitimine yönelik görüşlerini ortaya çıkarabilmek için kullanılan "STEM eğitimi öğretmen adayları yarı yapılandırılmış görüşme formu" araştırmacılar tarafından geliştirilmiştir. Yarı yapılandırılmış görüşme formu geliştirilirken literatür taraması yapılmıştır (Alumbaugh, 2015; Dailey, 2013; Eroğlu \& Bektaş, 2016; Evans, 2015; Hsu, Purzer, \& Cardella, 2011; Kenney, 2013; Lee, Park, \& Kim, 2013; Owens, 2014; Shon, 2015; Thomas, 2014; Turner, 2013; Wang, 2012; Wang ve diğerleri, 2011; Yıldırım, 2016a; Y1ldırım, 2016b; Y1ldırım \& Selvi, 2016). Literatür taraması sonucunda 14 sorudan oluşan yarı yapılandırılmış görüşme formu oluşturulmuştur. Oluşturulan görüşme formuyla ilgili olarak STEM konusunda 3 proje yapmış ve araştırmaları olan iki uzmandan görüş alınmış ve görüşme soruları 10'a düşürülmüştür.

\subsection{Verilerin Analizi}

Araştırma kapsamında veriler ses kayıtları ve yarı yapılandırılmış görüşmeler yoluyla toplanmıştır. Yarı yapılandırılmış görüşmeler araştırmacılar tarafindan uygulama bitiminden sonra başlamış olup iki hafta boyunca devam etmiştir. Yarı yapılandırılmış görüşmeler sonucunda toplamda 450 dakikalık ses kaydı alınmıştır. Elde edilen kayıtlar araştırmacıların yanı sıra STEM alanında çalışmış bir uzman yardımı ile yazıya aktarılmıştır.

Yazıya dökülen verilerin analizi ve yorumu dört aşamalı bir şekilde gerçekleştirilmiştir. $\mathrm{Bu}$ aşamalar dokümanlardan elde edilen verilerin işlenmesi, verilerin kodlanması, kodların düzenlenmesi, bulguların tanımlanmas1-yorumlanması şeklindedir (Yıldırım \& Şimşek, 2006). İlk olarak veriler araştırmacılar tarafından ayrı ayrı kodlanmıştır. İlk kodlama süreci sonucunda araştırmacıların belirlediği kodların 115 tanesinin ortak olduğu, 25 tanesinin ortak olmadığ tespit edilmiştir. İlk kodlama açısından kodlayıcı güvenirliği [(Görüş Birliği/Görüş Birliği + Görüş Ayrılığ1)*100] formülü ile hesaplanmıştır (Miles \& Huberman, 1994). Bu araştırma için kodlayıcı güvenirliği $((115 / 115+25) * 100)=\% 82$ olarak bulunmuştur. Daha sonra araştırmacılar ve uzman 25 kod üzerinde tartışmıştır. Tartışma sonucunda 10 kodun daha çalışmaya eklenip, geri kalan 15 kodun ise çıkarılmasına karar verilmiştir. $\mathrm{Bu}$ 
aşamadan sonra veriler düzenlenmiş, temalara göre gruplandırmalar yapılmıştır. Gruplandırılan veriler frekans ve yüzde değerleri şeklinde sunulmuştur.

\section{BULGULAR}

Çalışmanın bu kısmında öğretmen adaylarına görüşmelerde sorulan her bir sorunun analizi sonucunda elde edilen bulgulara yer verilmiştir. Bu doğrultuda öğretmen adaylarına sorulan ilk soru olan "STEM denildiğinde akınıza gelen kelimeler nelerdir?" sorusuna verilen cevapların dağılımı Tablo 2'de sunulmuştur.

Tablo 2. "STEM denildiğinde akınıza gelen kelimeler nelerdir?" sorusuna verilen cevaplar

\begin{tabular}{lcclcc}
\hline Kodlar & $\mathbf{f}$ & $\mathbf{\%}$ & Kodlar & f & $\%$ \\
\hline Yaratıcılık/Hayal gücü & 22 & 55,0 & Ortak çalışma & 2 & 5,0 \\
Entegrasyon & 18 & 45,0 & Probleme dayalı öğrenme & 1 & 2,5 \\
Üretim & 16 & 40,0 & Proje tabanlı öğrenme & 1 & 2,5 \\
21 yy. yaşam becerileri & 14 & 35,0 & Yapılandırmacı yaklaşım & 1 & 2,5 \\
Tasarım & 14 & 35,0 & Fen okuryazarlığ 1 & 1 & 2,5 \\
Eleştiri & 10 & 25,0 & Robot & 1 & 2,5 \\
Problem çözme & 9 & 22,5 & Mucitlik & 1 & 2,5 \\
Merak & 9 & 22,5 & Singapur matematiği & 1 & 2,5 \\
Özgüven & 4 & 10,0 & Motivasyon & 1 & 2,5 \\
Anlamlı öğrenme & 4 & 10,0 & İletişim & 1 & 2,5 \\
Yaklaşım & 3 & 7,5 & Mesleki eğitimi & 1 & 2,5 \\
Ekonomi & 2 & 5,0 & Bilimsel süreç becerileri & 1 & 2,5 \\
Sanat & 2 & 5,0 & Kendini ifade etme & 1 & 2,5 \\
Bilgisayar & 2 & 5,0 & Başarı & 1 & 2,5 \\
\hline
\end{tabular}

Tablo 2 incelendiğinde öğretmen adaylarının STEM'i çok sayıda kavramla ilişkilendirdiği görülmektedir. Öğretmen adaylarının \%55'i "Yaratıcılık/Hayal Gücü”, \%45'i “Entegrasyon”, \%40’1 “Üretim”, \%35'i “21 yу. yaşam becerileri ve tasarım”, \%25'i “Eleştiri”, \%22,5'i "Problem Çözme ve Merak" kelimelerini STEM ile ilişkilendirmişlerdir.

Öğretmen adaylarının STEM eğitimine yönelik görüşlerinin dağılımı Tablo 3 'te sunulmuştur.

Tablo 3. STEM eğitimine yönelik görüşlerine dağılımı

\begin{tabular}{lcc}
\hline Kodlar & f & \% \\
\hline Problem çözme becerisinin gelişmesini sağlar. & 10 & 25,0 \\
Öğrenilen bilgilerin günlük yaşamla ilişkilendirilmesini sağlar. & 8 & 20,0 \\
Ekonomik ve teknolojik gelişme sağlar. & 6 & 15,0 \\
Üst düzey düşünme becerilerinin gelişmesini sağlar. & 5 & 12,5 \\
Öğrencileri öğrenme konusunda cesaretlendirir. & 5 & 12,5 \\
Yaratıcıllk ve merak duygusunun gelişmesini sağlar. & 4 & 10,0 \\
STEM disiplinlerine karşı öğrencilerin ilgi ve tutumlarını geliştirir. & 4 & 10,0 \\
Yaparak-yaşayarak öğrenmeyi sağlar. & 3 & 7,5 \\
Disiplinler arası bağlantı kurmayı sağlar. & 3 & 7,5 \\
21. yy. yaşam becerilerinin gelişmesini sağlar. & 2 & 5,0 \\
Donanımlı bireylerin yetiştirilmesini sağlar. & 2 & 5,0 \\
Hayat boyu öğrenmeyi sağlar. & 1 & 2,5 \\
\hline
\end{tabular}

Tablo 3 incelendiğinde öğretmen adaylarının STEM eğitimine yönelik çeşitli olumlu görüşlerinin olduğu görülmektedir. Öğretmen adaylarının \%25'i "Problem çözme becerisinin gelişmesini sağlar.”, \%20'si “Öğrenilen bilgilerin günlük yaşamla ilişkilendirilmesini sağlar.”, \%15'i “Ekonomik ve teknolojik gelişme sağlar.”, \%12,5'i “Üst düzey düşünme becerilerin gelişmesini sağlar ve öğrencileri öğrenme 
konusunda cesaretlendirir." yönünde görüşler belirtmişlerdir. Bu soruya ilişkin öğretmen adaylarının görüşlerinden bazıları aşağıda verilmiştir:

$\ddot{O}_{24}$ : Problem çözmeyi, eleştirel düşünmeyi, iyi bir iletişim kurmayl, inovasyonu, özgüveni, sorumluluk duygusunu, empatiyi ve daha birçok şeyi geliştirir.

$\ddot{O}_{17}$ : Çocuğun yaratıcılı̆̆ını ön plana çıkartıp merak duygusunu açı̆̆a çıkarır.

$\ddot{O}_{13}$ : Öğrendiklerini yeni ve farkl problemlere transfer edebilmeyi să̆layan bir ĕgitim yaklaşımıdır.

$\ddot{O}_{9}:$ STEM eğitimi bir ülkenin gelişmişlik seviyesini arttırıp ekonomiye katkı sağlar.

$\ddot{O}_{2}$ : Öğrencileri doğrudan öğrenmeleri için cesaretlendirir.

Öğretmen adaylarına yöneltilen "STEM eğitimi ile ilgili yapılan yanlışlar nelerdir?" sorusuna verilen cevaplara ilişkin frekans ve yüzde değerleri Tablo 4 'te sunulmuştur.

Tablo 4. "STEM eğitimi ile ilgili yapılan yanlışlar nelerdir?” sorusuna verilen cevaplar

\begin{tabular}{lcc}
\hline Kodlar & f & \% \\
\hline Fen deneyleri ile yapılan uygulamalar STEM eğitimi değildir. & 34 & 85,0 \\
STEM eğitimi yöntem, teknik ve strateji değildir. & 28 & 70,0 \\
STEM eğitimi sadece legolar ile yapılmaz. & 27 & 67,5 \\
Robotik setler ile verilen eğitim STEM eğitimi değildir. & 26 & 65,0 \\
İki ya da üç disiplinin aynı anda kullanılması STEM eğitimi değildir. & 23 & 57,5 \\
Her yapılan etkinlik STEM eğitimi değildir. & 17 & 42,5 \\
Kodlama eğitimleri STEM eğitimi değildir. & 17 & 42,5 \\
Materyal tasarım dersleri STEM eğitim dersleri değildir. & 16 & 40,0 \\
STEM eğitim sadece üstün yeteneklilere verilmez. & 14 & 35,0 \\
STEM eğitimi sadece materyal odaklı değildir. & 10 & 25,0 \\
STEM eğitimi sadece fizik temelli değildir. & 2 & 5,0 \\
\hline
\end{tabular}

Tablo 4 incelendiğinde, öğretmen adaylarının en çok verdiği cevabın "Fen deneyleri ile yapılan uygulamalar STEM eğitimi değildir." olduğu görülmüştür. Bunu takip eden diğer popüler cevaplar ise "STEM eğitimi yöntem, teknik ve strateji değildir", "STEM eğitimi sadece legolar ile yapılmaz." ve "Robotik setler ile verilen eğitim STEM eğitimi değildir." şeklindedir. Bu soruya ilişkin bazı öğretmen adaylarının cevaplarına aşağıda yer verilmiştir:

$\ddot{O}_{37}:$ Robotik yapanlar STEM yaptı̆̆ını zannediyor. Daha sonra böyle bir algı yerleşiyor.

$\ddot{O}_{26}$ : STEM eğitimine lego demek yanlış olur. Legolar STEM eğitiminde kullanılan araçlardır.

$\ddot{O}_{13}$ : STEM bir yaklaşım olmaktan ziyade bir yöntem olarak görülmektedir.

$\ddot{O}_{9}:$ Fen deneyleri yapanlar STEM yaptıklarını zannediyorlar. Ama deneylerde sadece fen konularının ögretilmesi söz konusudur. STEM için tüm disiplinlerin kullanılmasl gerekecektir.

Öğretmen adaylarına yöneltilen "STEM eğitimi okul öncesi ve ilköğretim düzeyinde verilmeli midir?" sorusuna verilen cevaplara ilişkin frekans ve yüzde değerleri Tablo 5 'te sunulmuştur. 
Tablo 5. "STEM eğitimi okul öncesi ve ilköğretim düzeyinde verilmeli midir?" sorusuna verilen cevaplar

\begin{tabular}{llcc}
\hline Kodlar & & f & \% \\
\hline \multirow{2}{*}{ STEM eğitimi okul öncesi ve ilköğretimde verilmelidir. } & Evet & 40 & 100,0 \\
& Hayır & - & - \\
\hline
\end{tabular}

Tablo 5 incelendiğinde öğretmen adaylarının tamamının STEM eğitiminin okul öncesi ve ilköğretim döneminde verilmesi gerektiğine yönelik cevap verdikleri görülmektedir.

Öğretmen adaylarına yöneltilen "STEM eğitimi ilköğretim ve okulöncesi dönemde neden önemlidir?" sorusuna verilen cevaplara ilişkin frekans ve yüzde değerleri Tablo 6'da sunulmuştur.

Tablo 6. "STEM eğitimi ilköğretim ve okulöncesi dönemde neden önemlidir?" sorusuna verilen cevaplar

\begin{tabular}{lcc}
\hline Kodlar & f & \% \\
\hline Yaratıcılık ve merak duygusunu geliştirdiği için önemlidir. & 24 & 60,0 \\
Fen, matematik, teknoloji, mühendislik disiplinlerin temelini oluşturduğu & 17 & 42,5 \\
için önemlidir. & 12 & 30,0 \\
Günlük yaşamla ilişkilendirmeyi sağladı̆̆ı için önemlidir. & 9 & 22,5 \\
Fen, matematik, teknoloji, mühendislik disiplinlerine karşı olumlu tutum & 7 & 17,5 \\
geliştirmesi için önemlidir. & 7 & 17,5 \\
Çocukların eleştirel düşünme becerilerini geliştireceği için önemlidir. & 5 & 12,5 \\
Öğrenilen bilgilerin somutlaştırılmasını sağladığı için önemlidir. & 5 & 12,5 \\
Fen, matematik gibi derslere karşı motivasyonu arttırdığı için önemlidir. & 5 & 12,5 \\
Öğrencilerin yeteneklerinin fark edilmesini sağladığı için önemlidir. & 4 & 10,0 \\
21. yy. becerilerini geliştirdiği için önemlidir. & 4 & 10,0 \\
Problem çözme ve bilimsel süreç becerilerini geliştirdiği için önemlidir. & 4 & 10,0 \\
Hayal gücünü geliştirdiği için önemlidir. & 3 & 7,5 \\
Yaparak yaşayarak öğrenmeyi sağladığı için önemlidir. & 1 & 2,5 \\
Özgüveni geliştirdiği için önemlidir. & \\
Matematik okuryazarlığını geliştirdiği için önemlidir. &
\end{tabular}

Tablo 6'daki bulgular incelendiğinde öğretmen adaylarının STEM eğitiminin ilköğretim ve okul öncesi dönemdeki önemine ilişkin çok sayıda önemli gerekçe ortaya sundukları görülmüştür. Bu gerekçeler arasında en çok vurgu yapılan düşünce "Yaratıcılık ve merak duygusunu geliştirdiği için önemlidir." düşüncesidir. Ardından "Fen, matematik, teknoloji, mühendislik disiplinlerin temelini oluşturduğu için önemlidir.” ve "Günlük yaşamla ilişkilendirmeyi sağladığı için önemlidir.” gibi düşünceler gelmektedir. Bu soruya ilişkin bazı öğretmen adaylarının cevaplarına aşağıda yer verilmiştir:

$\ddot{O}_{21}$ : Illköğretim ve okul öncesinde STEM eğitimi önemlidir. Çünkü çocukların fen ve matematik eğitiminin temelleri bu dönemde atıliyor.

$\ddot{O}_{24}$ : STEM eğitimindeki en önemli zaman ilkögrretim ve okul öncesi dönemdir. Çünkü atasözümüzde de geçtiği gibi “Ăgaç yaş iken eğilir.” Bu dönemlerde bireylerin yaratıcılıkları ve hayal güçleri had safhadadır ve büyüdükçe azalır. Bu yüzden erken yaşlardan itibaren bu özellikler öne çıkarllmalıdır.

Ö $_{26}$ : Çocuklara küçük yaşta fen, teknoloji, mühendislik ve matematik disiplinlerinin temellerini vermeliyiz. Onlara bu alanları sevdirmeliyiz. 
$\ddot{O}_{17}$ : Çocuk, ilkögretimde matematik ve fen derslerini görecektir. Çocuğa göre bu dersler zordur. Çocuğa bu dersler sevdirilmelidir. Bu yüzden STEM eğitimi ilkögretim ve okul öncesi dönemlerinde önemlidir. STEM eğitimi ile birlikte çocuğun bu derslere karşı olumlu tutum sergilemesi sağlanır.

$\ddot{O}_{11}$ : Ilkögretim ve okul öncesi dönemdeki çocukların yaratıcılık, merak, eleştirel düşünme gibi becerileri çok fazladır. STEM eğitimi bu dönemden itibaren verilirse, çocukların bu becerileri geliştir.

$\ddot{O}_{33}$ : STEM eğitimi, çocukların fen ve teknolojiyi sevmesine neden olur. Bu sayede çocuklar yeni ürünler geliştirirler. Çocukların geliştirdikleri yeni ürünler ile birlikte özgüvenleri artar.

$\ddot{O}_{38}$ : Illköğretim yıllarında çocuklarının ĕgitimleri iyi verilmelidir. Bunun için STEM eğitimi önemlidir. Örneğin matematik dersinin iyi anlaşılması, matematik okuryazarlığı için önemlidir.

Öğretmen adaylarına yöneltilen "STEM eğitimi çocukların hangi özelliklerinin gelişmesine katkı sağlar?” sorusuna verilen cevaplara ilişkin frekans ve yüzde değerleri Tablo 7'de sunulmuştur.

Tablo 7. "STEM eğitimi çocukların hangi özelliklerinin gelişmesine katkı sağlar?" sorusuna verilen cevaplar

\begin{tabular}{lcc}
\hline Kodlar & f & \% \\
\hline Yaratıcılığı geliştirmesi & 25 & 62,5 \\
Problem çözme becerisinin gelişmesi & 25 & 62,5 \\
Eleştirel düşünme becerisinin gelişmesi & 22 & 55,0 \\
Özgüven ve öz yeterliliğin gelişmesini sağlaması & 18 & 45,0 \\
Motivasyonun arttırması & 11 & 27,5 \\
Merak duygusunu geliştirmesi & 10 & 25,0 \\
Hayal gücünü geliştirmesi & 8 & 20,0 \\
Tasarım odaklı düşünme becerisinin gelişmesi & 8 & 20,0 \\
Ortak çalışma becerisinin gelişmesi & 8 & 20,0 \\
Buluş yapma becerisinin gelişmesi & 7 & 17,5 \\
Hoşgörü ve empati özelliğini geliştirmesi & 6 & 15,0 \\
İletişim becerisinin gelişmesi & 5 & 12,5 \\
Sorumluluk duygusunun gelişmesi & 3 & 7,5 \\
Tasarım/çizim becerilerini geliştirmesi & 1 & 2,5 \\
\hline
\end{tabular}

Tablo 7 incelendiğinde, öğretmen adaylarının \%62,5'i "Yaratıcılığı ve problem çözme becerisini geliştirdiğini", \%55'i "Eleştirel düşünme becerisini geliştirdiğini”, \%45'i “Özgüven ve öz yeterliliğin gelişmesini sağladığını”, \%27,5'i "Motivasyonu arttırdığını”, \%25'i "Merak duygusunu arttırdığını” ifade etmiştir. Bu soruya ilişkin bazı öğretmen adaylarının cevaplarına aşağıda yer verilmiştir:

$\ddot{O}_{2}$ : Günlük yaşamda karşılaştıkları problemlere faklı çözümler üretebilmelerini sağlar.

$\ddot{O}_{8}$ : Bireysel ve grup halinde çalışmak çocukların özgüven ve öz yeterliliklerinin gelişmesini sağlar.

$\ddot{O}_{9}:$ STEM ĕgitimi ile bir bireye kazandırllması să̆lanan en büyük beceri özgüvendir. Bu sayede hem mesleki açıdan yetenekli, farklı bakış açısında sahip bir kişi hem de günlük yaşamda özgüvenli ve ne yaptığını bilen bir kişi olmasını sağlar. 
$\ddot{O}_{24}$ : STEM eğitimi, öğrencileri düşünmeye ittiğinden çocukların yaratıcılık ve hayal gücünü geliştirir.

$\ddot{O}_{26}$ : Çocukların 21. yy. yaşam becerisi olan empati ve hoşgörü özelliklerinin gelişmesini sağlar.

Öğretmen adaylarına yöneltilen "Öğretmen olduğunuzda sınıfınızda STEM uygulamalarına yer vermek ister misiniz?” sorusuna verilen cevaplara ilişkin frekans ve yüzde değerleri Tablo 8'de sunulmuştur.

Tablo 8. "Öğretmen olduğunuzda sınıfınızda STEM uygulamalarına yer vermek ister misiniz?" sorusuna verilen cevaplar

\begin{tabular}{lcc}
\hline Kodlar & f & \% \\
\hline STEM uygulamalarına derste yer vereceğim. & 25 & 62,5 \\
STEM uygulamalarına derste yer vermeyeceğim. & 10 & 25,0 \\
STEM uygulamalarına derste kullanıp kullanılmaması & 5 & 12,5 \\
konusunda kararsızım. & 5 \\
\hline
\end{tabular}

Tablo 8 incelendiğinde öğretmen adaylarının \%62,5'i STEM uygulamalarını derslerinde uygulamayı düşünürken, \%25'i uygulamayı düşünmediği ve \%12,5'inin ise kararsız olduğu tespit edilmiştir.

STEM uygulamalarına derste yer vermeyeceğini düşünen veya bu konuda karasız olan öğretmen adaylarına bunun nedeni sorulmuştur. $\mathrm{Bu}$ soruya verilen cevaplara ilişkin frekans ve yüzde değerleri Tablo 9'da sunulmuştur.

Tablo 9. "Öğretmen olduğunuzda sınıfınızda STEM uygulamalarına derste neden yer vermek istemiyorsunuz veya kararsızlık yaşıyorsunuz?" sorusuna verilen cevaplar

\begin{tabular}{lcc}
\hline Kodlar & f & \% \\
\hline STEM eğitimi konusunda alan bilgisi eksiğim var. & 6 & 40 \\
Mühendislik hakkında yeterli bilgi sahibi değilim. & 4 & 26,6 \\
Fen ve Matematik konusunda kendimi yeterli hissetmiyorum. & 3 & 20 \\
Uygulamalar için sinıf ortamı ve zaman uygun değil. & 2 & 13,4 \\
\hline
\end{tabular}

Tablo 9 incelendiğinde öğretmen adaylarının \%40’ının STEM eğitimi konusunda alan bilgisi eksikliği olduğu, \%26,6'sının mühendislik hakkında yeterli bilgi ve donanıma sahip olmadığı, \%20'sinin fen ve matematik konusunda kendilerini yeterli hissetmedikleri ve \%13,4'ünün ise uygulamaları sınıfta yapmak için uygun bir ortam ve zamanın olmadığı yönünde düşünceye sahip oldukları tespit edilmiştir. Bu soruya ilişkin bazı öğretmen adaylarının cevaplarına aşağıda yer verilmiştir.

$\ddot{O}_{1}$ : STEM eğitimi faydalı ve okulda kullanılması gerekir. Ama STEM uygulamalarını derste yapacak yeterlilikte alan bilgisine sahip olmadı̆̆ımı düşünüyorum.

$\ddot{O}_{7}$ : Kendimi mühendislik eğitimi konusunda yeterli hissetmiyorum. Çünkü üniversitede bu konuda yeterli bilgi verilmedi. Bu yüzden uygulamayı düşünmüyorum.

$\ddot{O}_{20}$ : STEM uygulamalarının derste uygulanması için yeterli zaman ve malzemenin olması gereklidir. Malzemeler olmayacağından derste uygulamak istemiyorum.

$\ddot{O}_{30}$ : Fen ve matematik ĕgitimi konusunda kendimi yeterli hissetmediğim için uygulamak istemiyorum. 
STEM eğitimi uygulamaları sonrası öğretmen adaylarının mühendislik ve mühendise yönelik görüşlerindeki değişsimlere ilişkin bulgular Tablo 10'da sunulmuştur.

Tablo 10. Mühendislik ve mühendise yönelik öğretmen adaylarının görüşlerindeki değișim

\begin{tabular}{lcc}
\hline Kodlar & f & \% \\
\hline Mühendis ve mühendisliğe ilişkin görüşlerim değişti. & 30 & 75,0 \\
Mühendis ve mühendisliğe ilişkin görüşlerim değişmedi. & 10 & 25,0 \\
\hline
\end{tabular}

Tablo 10 incelendiğinde öğretmen adaylarının \%75'inin uygulama sonrasında mühendislik ve mühendise yönelik görüşlerinde bir değişme olduğu, \%25'inin ise görüşlerinde bir değişme olmadığı görülmektedir. Bu açıdan bakıldığında STEM eğitiminin öğretmen adaylarının bu konudaki görüşlerini olumlu yönde değiştirdiği söylenebilir.

STEM eğitimi uygulamaları sonrası öğretmen adaylarının mühendisliğe yönelik görüşlerinde ne tür değişim olduğuna ilişkin bulgular Tablo 11'de sunulmuştur.

Tablo 11. Mühendisliğe yönelik öğretmen adaylarının görüşlerindeki değişiklikler

\begin{tabular}{lcc}
\hline Kodlar & f & \% \\
\hline Mühendisliğin hem erkek hem de kızlara uygun bir meslek olduğunu anladım. & 18 & 45,0 \\
Mühendislilerin işçi olduğu düşüncem değişti. & 3 & 7,5 \\
Mühendisliğin basit bir meslek olduğunu düşünüyordum. & 3 & 7,5 \\
Mühendislerin gözlüklü kişiler olduğu düşuncesi değişti. & 2 & 5,0 \\
Mühendisliğin fen, teknoloji ve mühendislikle ilişkili olduğunu anladım. & 2 & 5,0 \\
Mühendisliğin sadece kavram ve semboller olduğunu düşünüyordum. & 1 & 2,5 \\
Mühendisliği öğretmenlerinde bilmesi gerektiğini düşünüyorum. & 1 & 2,5 \\
Mühendislik eğitimi için STEM eğitiminin olmazsa olmaz olduğunu düşünüyorum. & 1 & 2,5 \\
Mühendisliğin önemli olduğunun farkına vardım. & 1 & 2,5 \\
\hline
\end{tabular}

Tablo 11 incelendiğinde öğretmen adaylarının \%45'i mühendisliğin sadece erkeklere özgü bir meslek olduğunu düşünürken uygulama sonrasında mühendisliğin hem erkek hem de kızlara uygun bir meslek olduğunu ifade ettikleri görülmüştür. Öğretmen adaylarının \% 7,5'i uygulama öncesinde mühendisleri işçi ve mühendisliğin basit bir meslek olduğunu; \%5'i mühendislerin sadece gözlüklü kişiler olduklarını; \%2,5'nin ise mühendisliği sadece kavram ve sembollerden oluştuğu düşündükleri ancak STEM eğitimi uygulamaları sonucunda görüşlerinin olumlu yönde değiştiğini söylemişlerdir. Ayrıca öğretmen adaylarının \%2,5'i mühendisliği öğretmenlerin bilmesi gerektiğini, mühendislik eğitimi için STEM eğitiminin olmazsa olmaz olduğunu ve mühendislik eğitiminin önemli olduğunun farkına vardıklarını belirtmişlerdir. Bu konuya ilişkin bazı öğretmen adaylarının görüşlerine aşağıda yer verilmiştir:

$\ddot{O}_{37}$ : Mühendisliğin bu kadar önemli bir alan olduğunun farkına vardım.

$\ddot{O}_{33}$ : Mühendisliğin sadece erkeklere özgü bir meslek olmadı̆̆ının farkına vardım.

$\ddot{O}_{31}$ : Mühendis denildiğinde aklıma basit bir işçilik geliyordu ama STEM ĕ̌itimi aldıktan sonra mühendis ve mühendisliğin ne demek olduğunu anladım.

$\ddot{O}_{26}:$ Fark ettim ki ben de mühendisi erkek olarak tanımliyordum ama mühendis sadece erkekler değil kızlar da mühendis olabilir. 
$\ddot{O}_{25}$ : STEM ĕgitiminden önce mühendisliğin öğretmenlikle bir ilgisinin olmadı̆̆ını düşünüyordum. Eğitimi aldıktan sonra ögretmenlerin de mühendisliğe karşı belli bir miktar bilgisinin olması gerektiğini düşünüyorum. $\ddot{O}_{21}$ : Mühendisliğin sadece kavramlar, semboller ve sayllar olduğunu zannediyordum ama STEM ĕgitimi aldiktan sonra her alanda olduğunun farkına vardım.

STEM eğitimi uygulamaları sonrası öğretmen adaylarının teknolojiye yönelik görüşlerinde ne tür değişimler olduğuna ilişkin bulgular Tablo 12'de sunulmuştur.

Tablo 12. Teknolojiye yönelik öğretmen adaylarının görüşlerindeki değişiklikler

\begin{tabular}{lcc}
\hline Kodlar & f & $\%$ \\
\hline Teknolojinin ekonomi için önemli olduğunun farkına vardım. & 16 & 40,0 \\
Teknoloji sadece robotik ve teknolojik araç-gereçler olduğunu düşünüyordum. & 14 & 35,0 \\
Teknolojinin sadece bilgisayar olduğunu düşünüyordum. & 10 & 25,0 \\
Teknolojinin hayatımızı her alana kolaylaştırdığını düşünmeye başladım. & 9 & 22,5 \\
Teknolojinin sadece elektrikli ev aletlerinin olduğunu düşünüyordum. & 4 & 10,0 \\
Teknolojin eğitimin kalitesini attırdığını düşünüyorum. & 4 & 10,0 \\
Teknolojinin tek başına bir disiplin olmadığı, fen, matematik ve mühendislik & 4 & 10,0 \\
bilgisinin de olması gerektiğini düşünüyorum. & 2 & 5,0 \\
Teknolojinin sadece ürün odaklı olduğunu düşünüyordum. & 1 & 2,5 \\
Teknolojinin zararlı olduğunu düşünüyordum. & 1 \\
\hline
\end{tabular}

Tablo 12 incelendiğinde, öğretmen adaylarının teknolojiyle ilgili çeşitli düşüncelerinin STEM eğitimi uygulamaları sonrasında olumlu yönde değiştiği görülmektedir. Bu konuya ilişkin bazı öğretmen adaylarının görüşlerine aşağıda yer verilmiş̧ir:

$\ddot{O}_{36}$ : Teknolojinin bizim hayatımız için ne kadar önemli olduğunu STEM ĕgitimiyle kavramış oldum.

Ö$_{26:}$ Teknolojinin bir ülkenin ekonomisinde çok büyük bir güç olduğunu ve çok önemli olduğunu ögrendim.

$\ddot{O}_{25}$ : Teknolojin sadece robotik yaklaşımlar ve uygulamalar olduğunu düşünüyordum.

$\ddot{O}_{18}$ : Teknoloji=Computer olarak biliyordum. Strf yazllışları benziyor diye. Eğitimden sonra bu görüşüm değişti.

$\ddot{O}_{12}$ : Teknolojinin sadece robotik, telefon gibi şeyler olduğunu sanıyordum. STEM eğitiminden sonra kalemin bile teknoloji olduğunun farkına vardım.

Öğretmen adaylarına yöneltilen "Fen, teknoloji, mühendislik ve matematik arasında nasıl bir ilişki vardır?" sorusuna verilen cevaplara ilişkin frekans ve yüzde değerleri Tablo 13'te sunulmuştur.

Tablo 13. "Fen, teknoloji, mühendislik ve matematik arasında nasıl bir ilişki vardır?" sorusuna verilen cevaplar

\begin{tabular}{lcc}
\hline Kodlar & f & $\%$ \\
\hline STEM eğitiminin oluşması için gerekli disiplinlerdir. & 13 & 32,5 \\
Fen ve matematik disiplinleri mühendisliği oluşturmaktadır. & 12 & 30,0 \\
Fen, teknoloji, mühendislik ve matematik birbirini tamamlayan disiplinlerdir. & 11 & 27,5 \\
Fen, matematik ve mühendislik disiplinleri teknolojiyi oluşturmaktadır. & 9 & 22,5 \\
Teknoloji için mühendislik bilgisi gereklidir. & 8 & 20,0 \\
\hline
\end{tabular}

Tablo 13'teki bulgular göstermektedir ki öğretmen adaylarının \%32,5'i fen, teknoloji, mühendislik ve matematiği "STEM eğitiminin oluşması için gerekli 
disiplinler olduğu”, \%30’u “fen ve matematik disiplinlerinin mühendisliği oluşturduğu", \%27,5'i "fen, teknoloji, mühendislik ve matematik birbirini tamamlayan disiplinler olduğu", $\% 22,5$ 'i "fen, matematik ve mühendislik disiplinlerinin teknolojiyi oluşturduğu" yönünde görüşler bildirmişlerdir. Bu konuya ilişkin bazı öğretmen adaylarının görüşlerine aşağıda yer verilmiştir:

Ö5: Fen ve matematik bilgiyi üretir. Sonra yaptırmak için süreç verilir ve tasarlamaları istenir (mühendislik). En sonunda teknoloji ürün ortaya çıkar. Bu sebepten dolayı dört temel disiplin birbirinden ayrllmaz bir bütündür ve bir arada kullanılmaları STEM'i oluşturur.

Ö9: Fen, teknoloji, mühendislik ve matematik birbirinden ayrlmaz bir bütündür. Bana göre hepsi birbirinin tamamlayıcısı niteliğindedir.

Ö40: Fen dersinin içinde matematik, matematik dersinin içerisinde fen bulunmaktadır.

\section{TARTIŞMA ve SONUÇ}

Çalışmanın birinci alt problemi doğrultusunda STEM eğitimi uygulamalarına yönelik sınıf öğretmeni adaylarının genel olarak görüşleri incelenmiştir. $\mathrm{Bu}$ doğrultudaki sonuçlar göstermektedir ki öğretmen adayları STEM eğitiminin problem çözme becerilerini, 21. yy. yaşam becerilerini, üst düzey düşünme becerilerini, yaratıcılık ve merak duygusunu geliştireceğini düşünmektedirler. Bunun yanı sıra, fen, teknoloji, mühendislik ve matematiğe karşı olumlu tutumlar geliştirmesini sağlayacağını, öğrenilen bilgilerin günlük yaşamla ilişkilendirilmesine firsat vereceğini ve ülkelerin ekonomik-teknolojik gelişmesine imkân sağlayacağını ifade etmişlerdir. Bu sonuçlar literatürdeki çalışmalarla uyum içerisindedir (Çınar, Pırasa, \& Sadoğlu, 2016; Egli, 2012; Eroğlu \& Bektaş, 2016; Kızılay, 2016; Lee ve diğerleri, 2013; Thomas, 2014; Wang, 2012; Y1ldırım, 2016a; Y1ldırım, 2016b).

Birinci alt problem çerçevesinde elde edilen diğer bir sonuç ise, öğretmen adaylarının STEM eğitimi ile ilgili yapılan yanlışlara ilişkin görüşlerine ilişkindir. Öğretmen adayları fen deneyleri ile yapılan uygulamaların, sadece lego, robotik ve kodlamalarla yapılan etkinliklerin STEM eğitimine uygun olmadığını, STEM eğitiminin sadece üstün yetenekli öğrencilere verilemeyeceği ve son olarak STEM eğitiminin materyal tasarım dersi ve Maker (materyal oluşturma) hareketi olmadığını söylemişlerdir. Ayrıca STEM eğitiminin bir yöntem, teknik ve strateji olmadığı aksine yöntem, strateji ve tekniğin STEM eğitimin öğretilmesinde kullanılan yollar olduğu üzerinde durmuşlardır. Son olarak öğretmen adayları iki ya da üç disiplinin aynı anda kullanılmasının STEM eğitimi olmayacağını ancak tüm disiplinler kullanıldığında STEM eğitimi olacağı üzerinde durmuşlardır. Bu sonuçlara paralel olarak birçok araştırmada STEM eğitimi ile ilgili kavram yanılgılarının olduğu üzerinde durulmuştur (Akgündüz, 2016; Morrison, 2006). Benzer şekilde Yıldırım ve Selvi (2016) çalışmasında öğretmen adaylarının STEM eğitimine yönelik kavram yanılgıları üzerine durmuştur. Benzer şekilde Eroğlu ve Bektaş (2016) STEM eğitimi ile ilgili kavram yanılgılarının olduğunu ifade etmiştir. Çalışmamız kapsamında STEM eğitimine yönelik var olduğu tespit edilen yanlışlıklar literatürdeki sonuçları destekler niteliktedir. Hem bu çalışmadan elde edilen sonuçlar hem de literatürdeki sonuçlar göstermektedir ki STEM eğitimine yönelik çeşitli kavram yanılgıları söz konusudur ve bu da STEM eğitiminin yeteri düzeyde anlaşılmadığını ve yanlış uygulandığını göstermektedir. 
Birinci alt problem doğrultusunda elde edilen sonuçlardan bir diğeri ise, öğretmen adaylarının STEM eğitimin çocuklar üzerindeki etkilerine yöneliktir. Öğretmen adayları STEM eğitiminin çocukların yaratıcı düşünme, problem çözme, eleştirel düşünme becerisi, özgüven ve öz yeterliliğinin gelişmesini sağlayacağı ve çocukların motivasyonunu arttıracağı üzerinde durmuşlardır. Ayrıca çocukların merak duygusunu, hayal gücünü, ortak çalışma ve tasarım odaklı düşünme becerisini geliştireceğini dile getirmişlerdir. STEM eğitiminin çocukların yetenek ve becerilerini geliştirdiğine dair literatürde benzer çalışmalar bulunmakta olup, çalışmamızda elde ettiğimiz sonuçlar literatürü destekler niteliktedir. (Cotabish, Dailey, Robinson, \& Hunghes, 2013; Kim \& Choi, 2012; Kwon, Nam, \& Lee, 2012; Park, Nam, Moore, \& Roehring, 2011; Riskowski, Todd, Wee, Dark, \& Harbor, 2009; Sahin, Ayar, \& Adıgüzel, 2014; Yıldırım, 2016a).

Birinci alt problem doğrultusunda elde edilen son sonuç ise, öğretmen adaylarının çoğunluğunun STEM uygulamalarına derslerinde yer vermeyi düşündüğü, diğerlerinin ise yer vermek istemediği veya karasızlık yaşadıkları şeklindedir. Öğretmen adaylarının STEM uygulamalarına derslerinde yer vermek istememesinin veya karasızlık yaşamasının nedenleri incelendiğinde ise, STEM eğitimi konusunda alan bilgisi, mühendislik bilgisi, fen ve matematik bilgilerinde eksiklerinin olduğu tespit edilmiştir. Bu açıdan bakıldığında STEM eğitiminin derslerde uygulanabilmesi için öğretmen adaylarına bu konu ile ilgili eğitimlerin verilmesi gerekmekte ve eğitim fakültesi müfredatlarında değişikliklere gidilerek eğitim fakültelerinde STEM disiplinlerine yönelik derslerin eklenmesi gerekmektedir. Benzer şekilde Yıldırım (2016b) öğretmenlerin STEM eğitimi konusunda olumlu görüşlerinin olduğu ancak bu konuda kendilerini yeterli hissetmediklerini tespit etmiş olup, STEM eğitiminin uygulanabilmesi için uygun ortam ve imkanların olması gerektiğini vurgulamıştır.

Çalışmanın ikinci alt problemi kapsamında STEM eğitimi uygulamaları sonucunda sınıf öğretmeni adaylarının mühendisliğe yönelik görüşlerindeki değişim araştırılmıştır. Bu doğrultudaki en genel sonuç, öğretmen adaylarının STEM eğitimi öncesinde mühendislik ile ilgili kavram yanılgıları olduğu ancak bu yanılgıların uygulama sonrasında olumlu yönde değiştiği şeklindedir. Özellikle öğretmen adaylarının mühendisliğin erkeklere uygun bir meslek olduğu yönünde bir kavram yanılgısına sahip olduğu belirlenmiştir. Literatür incelendiğinde, çalışmaların çoğunda mühendisliğin erkeklere uygun bir meslek olduğu ve bunun da yanlış bir durum olduğu üzerinde durulmaktadır (Cunningham, Lachapelle, \& LindgrenStreicher, 2005; Fralick, Kearn, Thompson, \& Lyons, 2009; Knight \& Cunningham, 2004; Meihholdt \& Murray, 199; Sherriff \& Binkley, 1997; Y1ldırım, 2016a). Mühendislik ve mühendisliğe ilişkin öğretmen adaylarında var olduğu belirlenen bir diğer kavram yanılgısı ise "mühendislerin işçi olarak görülmesi” şeklindedir. Literatür incelendiğinde bu yanılgının bazı araştırmacılar tarafından da tespit edildiği görülmektedir (Cunningham ve diğerleri, 2005; Knight \& Cunningham, 2004).

Çalışmanın üçüncü alt problemi doğrultusunda öğretmen adaylarının teknoloji ile ilgili görüşleri incelenmiştir. Öğretmen adaylarının teknoloji ile ilgili birçok kavram yanılgılarının olduğu ve STEM eğitimi sonucunda bu kavram yanılgılarının olumlu yönde değiştiği tespit edilmiştir. Öğretmen adaylarının özellikle teknolojin sadece bilgisayar ve ev araç-gereçleri olmadığının farkına vardıkları anlaşılmıştır. Ayrıca teknolojinin bir süreç olduğunun ve zararlı olmadığının farkına vardıkları tespit edilmiştir. Son olarak teknolojinin eğitimin kalitesini arttırdığını ifade 
etmişlerdir. Benzer şekilde Metin, Birişçi ve Coşkun (2013) teknolojinin eğitim kalitesini arttırdığını belirtmiştir.

Çalışmanın dördüncü alt probleminde STEM eğitimi uygulamaları sonucunda öğretmen adaylarının STEM disiplinleri arasındaki ilişkiye yönelik görüşleri araştırılmıştır. $\mathrm{Bu}$ doğrultuda en genel sonuç, fen ve matematik disiplinlerin mühendisliği ve fen-matematik-mühendislik bilgisinin ise teknolojiyi oluşturduğu şeklindedir. Ayrıca öğretmen adayları bu disiplinlerin birbirini tamamladığını ve STEM'i oluşturduğunu ifade etmişlerdir. Kızılay (2016) çalışmasında benzer sonuçlara ulaşmıştır.

Sınıf öğretmenliğinde okuyan öğretmen adaylarının, eğitim verdikleri yaş grubu, akademik ve mesleki gelişimleri açısından STEM eğitimini bilmeleri ve derslerinde uygulayabilmeleri önemlidir. Bu açıdan bakıldığında bu çalışma, sınıf öğretmeni adayları ile STEM eğitimin incelendiği ilk çalışma olması açısından önemlidir. Bu çalışmanın, STEM eğitiminin özellikle sınıf öğretmeni adaylarına yönelik yapılacak çalışmaların etkilerini ortaya çıkarmak için yol gösterici nitelikte olacağı düşünülmektedir

\section{5. ÇALIŞMANIN SINIRLILIKLARI ve ÖNERÍLER}

$\mathrm{Bu}$ çalışma öğretmen adaylarının STEM eğitimi, mühendislik, teknoloji ve STEM disiplinlerinin arasındaki ilişkiye yönelik görüşlerinin neler olduğunu belirlemek amacıyla yapılmıştır. Bu çalışma öğretmen adaylarının STEM eğitimi, mühendislik, teknoloji ve STEM disiplinlerinin arasındaki ilişkiye yönelik görüşleri ile sınırlandırılmıştır. Ayrıca çalışma eğitim fakültesi sınıf öğretmenliğinde eğitime devam eden 3. sınıf öğrencileri ile 2016-2017 eğitim-öğretim yılı güz dönemi ile sınırlıdır. Bu sınırlılık incelendiğinde STEM eğitimiyle ilgili yapılacak çalışmalar farklı sınıf düzeylerinde ve farklı bölümlerde okuyan öğretmen adaylarıyla gerçekleştirilebilir. Bunun yanı sıra sınıf öğretmenliği lisans programında STEM eğitimi verilmesini sağlayacak seçmeli veya zorunlu dersler açılabilir. Çünkü sınıf öğretmenliği çocuklara temel eğitimlerin verildiği yerlerdir.

Bunların yanında çalışma sonucunda öğretmen adaylarının STEM alan bilgisi konusunda yetersiz oldukları tespit edilmiştir. Dolayısıyla STEM eğitimi konusunda öğretmen ve öğretmen adaylarının alan bilgisi eksikleri giderilmeli ve sınıflarında STEM uygulamalarını gerçekleştirebilmeleri için STEM Pedagojik Alan Bilgisi (STEM PAB) modelleri üzerinde durulmalı ve alt yapısı açıklanmalıdır. Bunun yanında eğitim fakültelerinin Fen Bilgisi, Matematik, Sınıf ve Okulöncesi öğretmenliği bölümlerinde STEM disiplinlerin öğretimine yönelik dersler eklenmelidir. Öğretmenlerin STEM alan bilgisi eksiklerin giderilmesi ve STEM PAB modellerini öğrenebilmeleri için uzun soluklu hizmet içi eğitimler verilmelidir. Son olarak STEM uygulamalarının sınıf ortamında gerçekleştirilebilmesi için MEB müfredatında değişikliklere gidilmeli ve gerekli ortam hazırlanmalıdır. 


\section{KAYNAKLAR}

Abdullah, N., Halim, L., \& Zakaria, E. (2014). VStops: A thinking strategy and visual representation approach in mathematical word problem solving toward enhancing STEM literacy. Eurasia Journal of Mathematics, Science \& Technology Education, 10(3), 165-174.

Akbiyık, C., \& Kalkan-Ay, G. (2014). Perceptions of pre-school administrators and teachers on thinking skills instruction: a case study. Hacettepe Üniversitesi Eğitim Fakültesi Dergisi, 29(1), 01-18.

Akgündüz, D. (2016). STEM'i Rahat Bırakın: Türkiye'de STEM adına yapılan hatalar ve öneriler. 3 Mart 2017 tarihinde http://www.egitimpedia.com/stemi-rahat-birakinturkiyede-stem-adina-yapilan-hatalar-ve-oneriler/ adresinden alınmıştır.

Alumbaugh, K. M. (2015). The perceptions of elementary STEM Schools in missouri. Unpublished doctoral dissertation, Lindenwood University, Missouri.

Benuzzi, S. (2015). Preparing future elementary teachers with a stem-rich, clinical, coteaching modeling of student teaching. Unpublished doctoral dissertation, California State University, California.

Bose, K., Tsamaase, M., \& Seetso, G. (2013). Teaching of science and mathematics in preschools of Botswana: The existing practices. Creative Education, 4(7), 43-51.

Creswell, J. W. (2003). Research design: Qualitative, quantitative, and mixed methods approaches. Thousand Oaks, CA: Sage.

Cotabish, A., Dailey, D. Robinson, A., \& Hunghes, G., (2013). The effects of a STEM intervention on elementary students' science knowledge and skills. School Science and Mathematics, 113(5), 215-226.

Cunningham, C. M., Lachapelle, C., \& Lindgren-Streicher, A. (2005). Assessing elementary school students' conceptions of engineering and technology. Retrieved from:http://engineering.nyu.edu/gk12/ampscbri/pdf/Assessing\%20Elementary\%20Sch ool\%20Students\%20Conceptions\%20of\%20Engineering\%20and\%20Technology.pdf.

Çınar, S., Pırasa, N., \& Sadoğlu, G. P. (2016). Views of science and mathematics preservice teachers regarding STEM. Universal Journal of Educational Research, 4(6), 14791487.

Dailey, D. D. (2013). The Effects of A STEM professional development intervention on elementary teachers. Unpublished doctoral dissertation, University of Arkansas, Little Rock.

Dorsen, J., Carlson, B., \& Goodyear, L. (2006). Connecting informal STEM experiences to career choices: Identifying the pathway. ITEST Learning Resource Center.

Egli, S. (2012). Using STEM education to promote 21 st century math skills. Unpublished master dissertation, Minot State University, North Dakota.

Erdoğan, S. Ç., \& Baran, G. (2005). Erken çocukluk döneminde matematik. Eğitim ve Bilim, 28(130).

Eroğlu, S., \& Bektaş, O. (2016). STEM eğitimi almış fen bilimleri öğretmenlerinin STEM temelli ders etkinlikleri hakkındaki görüşleri. Eğitimde Nitel Araştırmalar Dergisi Journal of Qualitative Research in Education, 4(3), 43-67.

Evasns, E. M. (2015). Preparing elementary pre-service teachers to integrate STEM: A mixedmethods study. Unpublished doctoral dissertation, Northern Illinois University, Illinois.

Fralick, B., Kearn, J., Thompson, S., \& Lyons, J. (2009). How middle schoolers draw engineers and scientists. Journal of Science Education and Technology, 18(1), 60-73.

Ginsburg, H. P., Lee, J. S., \& Boyd, J. S. (2008). Mathematics education for young children: What it is and how to promote it. Social Policy Report, 22(1), 1-24. 
Gonzalez, H. B., \& Kuenzi, J. J. (2012). Science, technology, engineering, and mathematics (STEM) education: A primer. Congressional Research Service, Library of Congress.

Hsu, M. C., Purzer, S., \& Cardella, M. E. (2011). Elementary teachers' views about teaching design, engineering, and technology. Journal of Pre-College Engineering Education Research, 1(2), 31-39.

Hudson, P., English, L., Dawes, L., King, D., \& Baker, S. (2015). Exploring links between pedagogical knowledge practices and student outcomes in STEM education for primary schools. Australian Journal of Teacher Education, 40(6), 134-151.

Kenney, M. (2013). Journeys, adventures, bridges and puzzles: A case study approach to understanding teachers' conceptions of STEM. Unpublished doctoral dissertation, Arizona State University, Arizona.

Kızılay, E. (2016). Fen bilgisi öğretmen adaylarının FETEMM alanları ve eğitimi hakkındaki görüşleri. The Journal of Academic Social Science Studies, 47, 403-417.

Kim, D. H., Ko, D. G., Han, M. J., \& Hong, S. H. (2014). The effects of science lessons applying STEAM education program on the creativity and interest levels of elementary students. Journal of the Korean Association for Science Education, 34(1), 43-54.

Kim, G. S., \& Choi, S. Y. (2012). The effect of creative problem solving ability and scientific attitude through the science based STEAM program in the elementary gifted students. Elementary Science Education, 31(2), 216-226.

Knight, M., \& Cunningham, C. (2004). Draw an engineer test (DAET): Development of a tool to investigate students' ideas about engineers and engineering. Proceedings of ASEE Annual Conference, Salt Lake City, Utah.

Kwon, S. B., Nam, D. S., \& Lee, T. W. (2012). The Effects of STEAM-based integrated subject study on elementary school students' creative personality. The Korea Society of Computer and Information, 17(2), 79-86.

Lee, J. W, Park, H. J., \& Kim, J. B. (2013). Primary teachers' perception analysis on development and application of STEAM education program. Elementary Science Education, 31(1), 47-59.

Metin, M., Birişçi, S., \& Coşkun, K. (2013). Öğretmen adaylarının öğretim teknolojilerine yönelik tutumlarının farklı değişkenler açısından incelenmesi. Kastamonu Ĕgitim Dergisi, 21(4), 1345-1364.

Meihholdt, C., \& Murray, S. (199). Why aren't there more women engineers? Journal of Women and Minorities in Science and Engineering, 5(3), 239-263.

Miles, M. B., \& Huberman, A. M. (1994). Qualitative data analysis (2nd edition). Thousand Oaks, CA: Sage.

Ostler, E. (2012). 21st century STEM education: A tactical model for long-range success. International Journal of Applied Science and Technology, 2(1), 28-33.

Owens, D. B. (2014). Elementary teachers' perceptıons of science, technology, engineering, and mathematics education in $k-5$ schools. Unpublished doctoral dissertation, University of Phoenix, Arizona.

Park, M., Nam, Y., Moore, T. J., \& Roehring, G. (2011). The impact of integrating engineering into science learning on student's conceptual understandings of the concept of heat transfer. Journal of the Korean Society of Earth Science Education, 4(2),89-101.

Riskowski, J. L., Todd, C. D., Wee, B., Dark, M., \& Harbor, J. (2009). Exploring the effectiveness of an interdisciplinary water resources engineering module in an eighthgrade science course. International Journal of Engineering Education, 25(1), 181-195.

Rogers, R. R., Winship, J., \& Sun, Y. (2015). Systematic support for STEM pre-service teachers: An authentic and sustainable four. In K. Dikilitaş. (Eds.). Innovative 
Professional Development Methods and Strategies for STEM Education, (pp. 73-90). Hershey, PA: IGI Global. doi: 10.4018/978-1-4666-9471-2.ch005

Sherriff, B. L., \& Binkley, L. (1997). The irreconcilable images of women, science, and engineering: A Manitoban program that is shattering the stereotypes. Journal of Women and Minorities in Science and Engineering, 3, 21-36.

Stohlmann, M., Moore, T., \& Roehrig, G. H. (2012) Considerations for teaching integrated STEM education. Journal of Pre-College Engineering Education Research (J-PEER), 2(1), 28-34.

Shon, L. N. (2015). Ethnographic case study of a high school science classroom: strategies in STEM education. Unpublished doctoral dissertation, Texas A\&I University, Texas.

Sahin, A. Ayar, M. C., \& Adıgüzel, T. (2014). STEM related after-school program activities and associated outcomes on student learning. Educational sciences: Theory \& Practice, 14(1), 309-322.

Thomas, T. A. (2014). Elementary teachers' receptivity to integrated science, technology, engineering, and mathematics (STEM) education in the elementary grades. Unpublished doctoral dissertation, University of Nevada, Reno.

Turner, K. B (2013). Northeast Tennessee educators' perception of STEM education implementation. Unpublished doctoral dissertation, East Tennessee State University, Tennessee.

Wang, H. H., (2012). A new era of science education: science teachers' perceptions and class room practices of science, technology, engineering, and mathematics (STEM) integration. Unpublished doctoral dissertation, Minnesota University, Minnesota.

Wang, H. H., Moore, T. J., Roehrig, G. H., \& Park, M. S. (2011). STEM integration: Teacher perceptions and practice. Journal of Pre-College Engineering Education Research ( $J$ PEER), 1(2), 1-13.

Yıldırım, B. (2016a). 7. Sınıf fen bilimleri dersine entegre edilmiş fen teknoloji mühendislik matematik (STEM) uygulamalar ve tam ögrenmenin etkilerinin incelenmesi. Yayınlanmamış doktora tezi, Gazi Üniversitesi, Ankara.

Y1ldirım, B. (2016b). An analyses and meta-synthesis of research on STEM education. Journal of Education and Practice, 7(34), 23-33.

Yıldırım, B., \& Altun, Y. (2014). STEM eğitimi üzerine derleme çalışması: Fen bilimleri alanında örnek ders uygulanmaları. In M. Riedler et al. (Ed.) Proceedings of VI. International Congress of Education Research, (vol. 4, pp. 239-248), Hacettepe Üniversitesi, Ankara.

Yıldırım, B., \& Altun, Y. (2015). STEM eğitim ve mühendislik uygulamalarının fen bilgisi laboratuar dersindeki etkilerinin incelenmesi. El-Cezeri Journal of Science and Engineering, 2(2), 28-40.

Y1ldırım, B., \& Sevi, M. (2016). Examination of the effects of STEM education integrated as a part of science, technology, society and environment courses. Journal of Human Sciences, 13(3), 3684-3695. 


\section{EXTENDED ABSTRACT}

Recently, with the increasing importance in interdisciplinary studies, countries have adapted innovative educational approaches in this regard. One of these innovative approaches is STEM. STEM is the association of the fields of science, technology, engineering and mathematics with daily life in an integrated way (Gonzalez \& Kuenzi, 2012; Y1ldırım \& Altun, 2014). The concept of STEM emerged in the United States of America (USA) for the first time in 2001. Although the name STEM emerged in 2001, its origin goes back to 1957. There are two important aspects about why this concept emerged in the USA. The first one is the decrease in the interest of American students to the fields of science, mathematics and engineering back then (Ostler, 2012). The second one is the worry that the USA will fall behind in the international platform economically and technologically.

STEM education is an approach which brings together different disciplines, which enables students to learn effectively and with high quality, which provides meaningful learning by associating between the learned information and daily life and which contributes to the development of 21 st century life skills. STEM education is an approach which enables individuals' skills of creative thinking, imagination, empathy and tolerance to develop and which is important in preparing individuals for the workforce of 21st century (Ostler, 2012; Yıldırım, 2016a, Yıldırım \& Altun, 2015). Accordingly, preparing children learning environments in which they can present their thinking skills and express themselves without restricting their imagination and in which they can be faced with problems suitable for their own age from pre-school and primary school onwards is important (Akbiylk \& Kalkan-Ay, 2014). STEM education is important in developing these features of children. Thus, STEM education should be given from early ages. At this point, teachers have important duties to perform. Teachers' having a sufficient level of education in these fields can help students to be interested and successful in these fields. Thus, it is important for pre-service primary school teachers to have sufficient skills and information about STEM education.

The objective of this study is to find out what the views of pre-service primary school teachers are about the association between STEM education, engineering, technology and STEM disciplines. For this purpose, answers were sought to the following questions. What are pre-service primary school teachers' views about STEM education instruction? What are preservice primary school teachers' views about engineering as a result of STEM education instruction? What are pre-service primary school teachers' views about technology as a result of STEM education instruction? What are pre-service primary school teachers' views about the association between STEM disciplines as a result of STEM education instruction?

In line with this objective, the study used case report, which is one of the qualitative research methods. Case report is a qualitative research method in which one or a few cases restricted within a specific period of time are examined thoroughly and in which cases or casedependent themes are defined (Creswell, 2003).

The study group consisted of 40 pre-service teachers chosen according to two criteria out of 50 students who were studying their third year in the department of primary school teaching. The first criterion was participation in STEM education instruction at least for 10 weeks and the second one was full participation in STEM education instruction (between 6 and 12 weeks). The instruction period of the study was 4 hours a week for 12 weeks.

Within the context of the study, "STEM education pre-service teachers semi-structured interview form" developed by the researchers was used to find out the views of pre-service teachers about STEM education.

The data in the study were collected through voice recordings and semi-structured interviews. Semi-structured interviews started by the researcher after the instruction ended and continued for two weeks. As a result of semi-structured interviews, a total of 450 minutes of voice recording was taken. The recordings were written down by the researchers and an expert who was studying in the field of STEM. The analysis and interpretation of the data written down was made in four stages. These stages were processing the data from documents, coding the data, organizing the codes, defining the results and interpreting the results (Y1ldirım \& Şimşek, 2006). 
In line with the first sub-problem of the study, pre-service teachers think that STEM education will develop problem solving skills, 21st century life skills, top level thinking skills, feelings of creativity and curiosity. In addition, they stated that STEM education will enable students to develop positive attitudes towards science, technology, engineering and mathematics, give students opportunities to associate learned knowledge with daily life and contribute to the economic-technological development of countries. These results are in line with the studies in literature (Çınar, Pırasa \& Sadoglu, 2016; Wang, 2012; Yıldırım, 2016a; Y1ldırım, 2016b).

Pre-service teachers stated that instruction through science experiments and activities conducted with only legos, robotic and coding were not suitable for STEM education, STEM education could not be given only to gifted students and lastly STEM education was not a material design lesson or Maker movement.

Pre-service teachers emphasized that STEM education will help to develop children's creative thinking, problem solving, critical thinking skills and self-confidence and selfsufficiency and also increase children's motivation. In addition, they also stated that it will develop children's feelings of curiosity, creativity, cooperation and design-oriented thinking skill. There are a great number of studies indicating that STEM education develops children's abilities and skills (Cotabish, Dailey, Robinson, \& Hunghes, 2013; Kim \& Choi, 2012; Kwon, Nam, \& Lee, 2012).

In line with the second sub-problem of the study, it was found that pre-service teachers had misconceptions about engineering before STEM education; however, these misconceptions were found to develop positively after the instruction. Pre-service teachers were found to have a misconception that engineering was an occupation for men. Other misconceptions of preservice teachers about engineering and engineers were that "engineers were considered as workers". When the literature is examined, it can be seen that this misconception was also found by some researchers, too (Cunningham, Lachapelle, \& Lindgren-Streicher, 2005; Knight and Cunningham, 2004).

In line with the third sub-problem of the study, it was found that pre-service teachers had a great number of misconceptions about technology and as a result of STEM education, these misconceptions were found to change positively. It was found that pre-service teachers realized that technology was not only computers and technological household utensils. In addition, it was found that they realized technology was a process as well as creating a product and that it wasn't harmful. Lastly, they expressed that technology increased the quality of education. Similarly, Birişçi and Çoşkun (2013) stated that technology increased the quality of education.

In the fourth sub-problem of the study, pre-service teachers were found to think that science and mathematics disciplines formed engineering and the knowledge of science, mathematics and engineering formed technology. In addition, pre-service teachers expressed that these disciplines completed each other and formed STEM. It is important for pre-service of primary school teaching department to know about STEM education and to apply it to their lessons in terms of their age groups and academic and occupational development. When considered from this point of view, this study is important for being the first one to examine STEM education with pre-service primary school teachers. It is thought that this study will be a guide in finding out the effects of STEM education, especially of the studies conducted for pre-service primary school teachers. 